\title{
Analisis Hubungan Instrumen Perdagangan Internasional dan Perjanjian Lingkungan Internasional (GATT dan CITES) dalam Perspektif. Hukum Perjanjian Internasional
}

\author{
Oleh : Sri Wartini
}

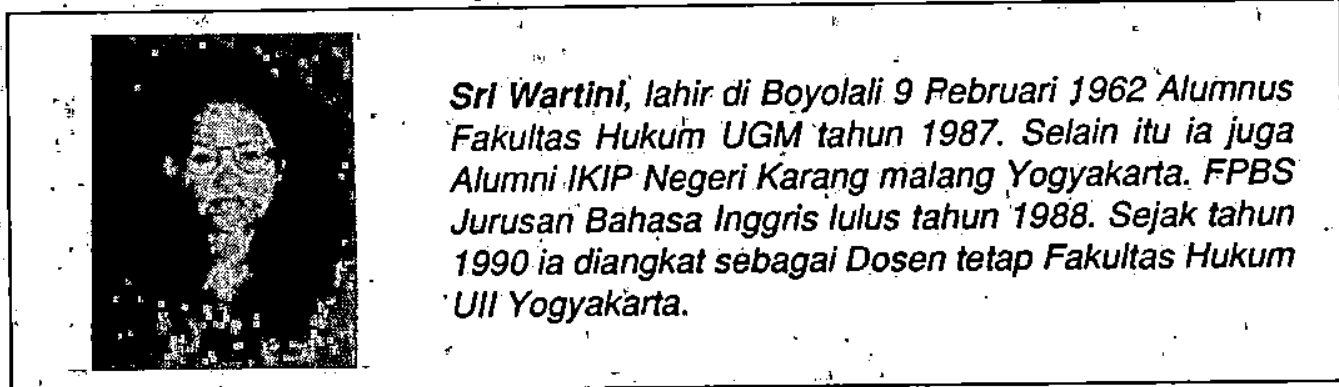

Pendahuluan

Interaksi antara perdàgangan intemasional "dan lingkungan merupakan suatu interaksi yang sudah setua perdagangan itu sendiri. Banyak sekali perbedaan-perbedaan pandangan mengenai "dampak" perdagangan internasional terhadap kualitas lingkungan. Ahli-ahli perdagangan berpendapat bahwa kemajuan perdàgangan merupakan suatu sumber untuk meningkatkan kesehatan dan mendorong penemuan teknologi baru. Sehingga kedua hal ini mendorong kemampuan masyarakat untuk melindungi danméningkatkanmutu lingkungan. Tetapi dilain pihak para ahli lingkungan berpendapat bahwa perdagangan 'bebas dapat membahayakan lingkungan. Khususnya jika kebijaksanaan lingkungan suatu negara itu lemah atau bähkan tidak ada.

Untuk mempertemukan kedua pendapat yang berbeda itu, maka' dimasukanlah instrumen perdagangan intermasional dalam perjanjian lingkungan internasionai atau sebaliknya. Walaupun disadári bahwa untuk mencari titik temu antara keduanya bukanlah meripakan sesuatu yang mudah dan sederhana. Karena seringtujuan kebijaksanaan lingkungan dan perdagangan intemasional konflik satu sama lain, tanpa ad́a struktur hukum yang mampu memberi solusi yang memuaskan.

Peraturan perdagangan internasional melalui proses GATT merupakan forum yang stabil untukmensosialisasikan hukum dan "kebijaksanáan. perdagangan , intemasional.Tetapi disisi lain GATT gagal 
untuk menangani masalah-masalah lingkungan secara memadai. Makalah ini akan memfoku'skan pada aspek-aspek perjanjian lingkungan internasional khususnya yang termuat dalam Convention on the International Trade in Endangered Species (CITES) dan peraturan perdagangan internasional dalam General Agreement on Tariffs and Trade (GATT).

\section{Alasan Menggunakan Instrument Perdagangan dalam Perjanjian Lingkungan Internasional}

Alasan-alasan menggunakan instrumen perdagangan dalam perjanjian Lingkungan Intemasional berbeda-beda berdasarkan subyek dari perjanjian tersebut. Perjanjian dimana instrumen perdagangan digunakan dalam perjanjian lingkungan ada tiga kategori : yaitu perjanjian untuk melindungi binatang langka (Agreement for the Protection of Endangered Species), perjanjian untuk melindungi negara pengimport dari produk-produk yang membahayakan lingkungan (Agreement to Protect the Environment of the Importing State from Harmful Products), dan perjanjian untuk melindungi "global commons". (Agreemnent to Protect the Global Commons). 'Dalam makalah ini, penulis hanya membahas salah satu dari tiga perjanjian tersebut, yaitu perjanjian untuk melindungi binatang langka.

\section{Perjanjian untuk Melindungi Binatang Langka}

Instrumen Perdagangan yang merupakan sesuatu yang fundamental untuk memproteksi binatang langka ialah Convention on the International Trade in Endangered Species (CITES). Walaupun ada perjanjian-perjanjian yang menggunakan pasal-pasal perdagangan secara insidental, tetapi CITES merupakan satu-satunya konvensi yang berusaha melindungi binatang langka dengan menggunakan instrumen perdagangan internasional. Sebagaimana yang dinyatakan oleh seorang komentator dalam hukum binatang langka internasional, yang menyatakan bahwa :

"CITES perhaps the most successful of all international treaties concemed with the conservation of wildlife. Its success is explained primarily by its basic principles ... The basic principles of CITES are quite straight forward. It regulates international trade in wild animals and plants which are listed in three appendixes to the convention"1

Kesuksesan CITES tidak hanya dibuktikan dalam keberhasilan mencegah penurunan populasi, tetaplada dua hal yang perlu dicatat dari konvenși ini. Pertama adanya pembatasan impor adalah sangat penting bagi proteksi binatang langka negara pengekspor. Karena negara pengimpor mempunyai kepentingan untuk melestarikan species tersebut dengan jalan pembatasan impor.Penolakan GATT untuk mengijinkan negara peserta membatasi perdagangan dalam 'rangka melindungi lingkungan diluarjurisdiksinya, disebabkan pada waktu pembentukan GATT tidak memperhatikan kedua hal tersebut. Alasan lain yang menyebabkan kesuksesan CITES ialah karena CITES berisi pembatasan perdaganganterhadapnegarabukan peserta. Dengan adanya pembatasan ini akan membantu menegakan sistem resiprokal

1). Simon Lyster, International Wild life Law,' hal 241, tanpa penerbit, tanpa tahun. 
yang ada antara negara pengimpor dan negara pengekspor.

\subsection{Pembatasan Ekspor oleh Para Pihak ..}

Hanya sedikit perjanjian yang bermaksud melindungi binatang langka secara eksplisit memaksakan larangan yang absolut pada ekspor binatang langka tersebut. Namun demikian, efek dari persyaratan untuk pemberian izin ekspor dalam CITES adalah untuk memaksakan suatu larangan terhadap ekspor jenis-jenis binatang langka seperti yang tercantum dalam Appendix I dan II. ${ }^{2}$

Yang lebih tipikal dari suatu larangan yang absolut adalah persyaratan untuk izin ekspor. Biasanya perjanjian ini menspesifikasi kondisi-kondisi untuk pemberian suatu izin, misalnya dalam CITES menentukan bahwa suatu izinekspor untukjenis "species" yang tercantum dalam Appendix II, izin hanya diberikan jika :

a. a scientific authority of the state of export has advised that such an export will not be detremental to the survival of that species;

b. a Management Authority of state of export is safisfied that the specimen was not obtained in contravention of the laws of that state for the protection of flora and fauna; and

c. a Management authority of the state of export is satisfied that any living specimen will be so prepared and shipped as to minimize the risk of injury, damage to health or cruel treatment". ${ }^{3}$

Kalau kita lihat sepintas lalu larangan dan pembatasan ekspor tersebut bertentangan dengan GATT pasal XI yang menyatakan :
"No prohibition or restriction other than duties, (taxes) or other charges whether made effective through quotas, import or export licences or measures, shall be instituted or maintained by any contracting party on the ... exportation ... of any product destined for the territory of any other contracting party".4

Mungkindapat diperdebatkan bahwa pembatasane ekspor binatang langka berada diluar larangan pasal XI karena ada pengecualian dalam pasal XI (1) $)^{5}$ yang menyatakan bahwa "export prohibitions or restrictions temporarily applied to prevent or relieve critical shortages of food stuff is or other product essential to the exporting contracting party". Oleh. karena itu merupakan suatu yang meragukan apakah GATT akan menganggap binatang langka sebagai suatu yang "essential" bagi negara pengeksport ? Dan , pembatasan jangka panjang yang ditentukan untuk pemulihan kembali species tertentu mungkin tidak akan diterapkan secara temporer. Bāhkan jika larangan-larangan dan pembatasanpembatasan ini bertentangan dengan pasal

2). D.S. Slocombe, "CITES, the Wildlife Tade and Sustainable Development" (1988), 16 (1), alternative ZO, dalam D. Vanderwang. et al, International Environnmental Law (Halifax; Dalhousie Law School 1992) hal 290. Dan untuk informasi lebih lanjut, baca Appendix I dan II CITES.

3). International Plenipotentiary Conference to conclude an International Convention On Trade in Certain Species of Wildlife : Convention On International Trade in Endangered Species of Wild Fauna \& Flora (1983) $12 \mathrm{I}>\mathrm{L}>\mathrm{M}>$ Hal 1085 Baca juga Pasal IV,CITES.

4). Baca, sebagai contoh, Final Report of the Panel in the matter of Canada's Landing Requirement for Pasific Coast Salmon and Herring, (16 Oktober 1989) paragrap 7.02

5). Pasal XI (1) GATT: 
XI (2), maka larangan dan pembatasan tersebut secara potensial jatuh dalam "exception" umum yang diatur dalam pasal XX yang menyatakan bahwa :

a. necessary to ptotect human, animal or plant life or health; ... (or) ${ }^{6}$

b. relating to the conservation of exhaustible natural resources if such measures are made effective in conjunction with restrictions on domestic production or consumption".?

Pembatasan ekspor binatang langka atau tanaman akan terjerat dalam pasal $\mathrm{XX}$ (b) jika mereka dapat membuktikan bahwa pembatasan itu perlu, sebagaimana kita ketahui bahwa perlindungan binatang dan tanaman langka berada dalam jurisdiksi suatu negara. Sekarang pertanyaan yang muncul adalah apakah pasal XX (b) GATT juga digunakan untuk melindungi species yang berada diluar jurisdiksi suatu negara ? ${ }^{8}$ Diasumsikan oleh GATT bahwa binatang langka dapat dikategorikan dalam "exhaustible natural resources" yang diatur dalam pasal XX (g). Walaupun motif utama konservasi dalam pasal ini bukanlah ekonomi tetapi ekologi, GATT menyatakan bahwa konservasi sumber alam telah memperluas perhatian kita terhadap lingkungan yang mencerminkan baik kepentingan ekonomi maupun non ekonomi.

Oleh karena itu pembatasan ekspor dibenarkan berdasarkan kepentingan ekologi, dan hal ini tidak seharusnya dianggap sebagai "Pembatasan perdagangan yang tersembunyi". Sehingga pembatasan ekspor yang diterapkan secara seimbang tidaklah menimbulkan suatu diskriminasi. Dalam hal pemberian izin impor yang diatur dalam CITES menyatakan bahwa lisensi import diberikan semata-mata bukan untuk tujuan komersial. ${ }^{9}$ Begitu juga dalam pemberian lisensi ekspor juga mengikuti persyaratan sebagaimana yang disyaratkandalam persyaratan ekspor, yaitu tidak semata-mata untuk tujuan komersial. Sedangkan ekspor species yang tidak begitu langka yang dimuat dalam appendix II, pemberian izin ekspor tidaklah berdasarkan persyaratan yang ada dalam izin impor. ${ }^{10}$

\subsection{Pembatasan Impor oleh Para Pihak \\ Jarang sekali perjanjian perlindungan} binatanglangka yang mengadakanlarangan impor secara absolut. Yang biása dilakukan ialah pemberian izin impor dengan syaratsyarat tertentu. Persyaratan umum yang harus dipenuhi, misalnya bahwa cara penángkapan binatang langka harus sesuai dengan hukum yang berlaku di negara pengekspor, atau negara pengekspor telah menentukan bahwa ekspor ini tidak menyebabkan kepunahan species tertentu dari negara pengekspor.

Kalau kita cari kesesuaian aturanaturan diatas dengan GATT nampaknya

6). Kasus yang baru saja terjadi yang berhubungan dengan masalah kesehatan adalah Thailand Restriction on Importation of and Intemational Taxes on cigarettes (antara USAdan Thailand) GATT Panel Report (5 Oktober 1990) D.S. 10/R

7). Pasal XX (b) GATT

8). UN Document, " International Enviromental LäwEmerging Trenda and Inplications for Transnational Corporations", (New York United Nations 1993) hal. 31. Baca juga pasal XX (b) GATT.

9). Baca CITES pasal III, "Regulation of Trade In Speciments of Species included in Apendix I, II, dan III.

10). Baca, Appendix I CITES 
sangatlah meragukankalau ada persesuaian, walaupun demikian tidak berarti bahwa peraturan pembatasan impor ini harus konflik dengan GATT. Pembatasan impor dalam rangka perlindungan lingkungan sering menimbulkan konflik antar negara. Misalnya konflik yang terjadi antara Mexico dan Amerika Serikat dalam hal ekspor "Tuna dan Dolphins". Menurut hukum Amerika ada larangan penangkapan dolphins, pada waktu musim ikan Tuna. ${ }^{11}$ Amerika ingin memberlakkukan peraturan ini bagi Mexico, oleh karena itu Amerika menjatuhkan sanksi perdagangan terhadap Mexico. Kalau saja Amerika memberlakukan ini bagi produk-produk domestik dan produk-produk impor dalam wilayahnya maupun dalam perbatasan, maka peraturan ini tidak bertentangan dengan GATT. Tetapi bukan peraturan ini diberlakukan diluar wilayah jurișdiksinya yang bukan saja mengatur produksinya, tetapi juga proses produksinya maka sanksi perdagangan ini merupakan pembatasan kuantitatif yang bertentangan dengan GATT pasal XI (1).

Dalam kasus "US - Mex́ico Tuna Dolphins dispute"12 menginterpretasikan bahwa pengecualian yang diatur dalam pasalXXGATT hanyadiperbolehkanuntuk perlindungan binatang langka dan tanaman di dalam jurisdiksi negara yang bersangkutan dan tidak diberlakukan di luar jurisdiksinya.

Keberatan yang paling prinsip adalah penerapan peraturan Amerika dalam "Tuna Dispute" untuk perlindungan "dolphins" dari cara penangkapannya yang akan mengakibatkan kepunahan mamalia yang diterapkan terhadap Mexico. Karena dalam penerapan ini tidakmenyebutkandi wilayah mana dolphins ini terancam. Sanksi yang dipaksakan oleh Amerika bukanlah merupakan peraturan perdagangan yang disetujui dalam "multilateral treaty" tetapi merupakan sanksi sepihakoleh suatu negara yang memaksakan jurisdiksinya dalam perlindungan lingkungan terhadap negara lain. Rejim sanksi sepihak/unilateral biasanya diterapkañ oleh negara besar terhadap negara kecil.

Pembatasan dalam impormerupakan bagian yang integral dari perjànjian internasional perlindungan binatang langka. Tanpa adanya pembatasan-pembatasan impor keefektifan perjanjian intemasional perlindungan binatang langka akan menjadi berkurang.

\subsection{Pembatasan Transit melalui Para Pihak}

Beberapa perjanjian intemasional untuk melindungi binatang langka, termasuk CITES, memaksakan pembatasan-pembatasan pada transit species-species yang dilindungi oleh perjanjian melalui wilayah para pihak. Sejak peraturan pembatasan transit diterapkan, ada perbedaan-perbedaan issue yang muncul terhadap penerapan peraturan pembatasan kuantitatif impor yang berbeda-beda. Peraturan-peraturan' ini mungkin konflik dengan GATT pasal V : 1. tentang kebebasan transit, yang menyatakan bahwa "There shall be freedom of transit,for traffic in transit to or from the territory of other contracting parties. ${ }^{13}$ Tidak boleh ada perbedaan yang diterapkan berdasarkan

11). Report of the panel, United States-Restrictions on imports of Tuna, (3 September 1991).

12). Ibid, Paragraph 5.27

13). Pasal V : 1 GATT 
perbedaan bendera kapal, atau berdasarkan suatu keadaan tertentu yang berhubüngan dengan kepemilikan suatu barang; kapal atau alat transportasi lainnya. GATT pasal $\mathrm{V}: 5$ menyatakan :

"With respect to all charges, regulations and formalities in connection with transit, each contracting party shall accord to traffic in transit to or from the territory of any other contracting party treatment no less favourable than the treatment accorded to traffic in transit to or from any third country". ${ }^{14}$

Oleh karena itu penerapan "exception" yang diatur dalam pasal XX menjadi relevån, dan analisis di atas akan diterapkan.

\section{Refleksi CITES dalam GATT}

Pada bagian ini akan dibahas pasalpasal perdagangan yang dimuat dalam perjanjian lingkungan internasional, khususnya yang diatur dalam CITES, yaitu untuk menganalisis apakah pasal-pasal tersebut bertentangan dengan GATT atau tidak? Sebelum kita bahas kesesuaian antara perjanjianlingkungan internasional.dengan GATT, adalah sangat penting untuk mengetahui persoalan-persoalan dan latar belakang GATT.

Hal pertama yang perlu kita mengerti ialah bahwa GATT hanya mengatur para pihak dan bukan mengatur pihak lain diluar GATT. Oleh karena itu GATT tidak dalam posisi untuk menilai apakah perjanjian lingkungan internasional konsisten dengan GATT atau tidak ? GATT memberikan kebebasan kepada para pihak untuk mengatur produk domestik, sepanjang tidak mendiskriminasikan produk-produk import atau berusaha melindungi produk domestik. Inimerupakan perlakuan nasional pasal III GATT.

Pasal XI GATT ${ }^{\text {is }}$ melarang pembatasan kuantitatif impor maupun ekspor. Kemudián pasal XIII, menyatakan bahwa tidak ada larangan atau pembatasan terhadap para pihak dalam perjanjian terhadap barang impor maupun ekspor dalam wilayah negara peserta, kecuali terhadap produk-produk serupa yang diproduksi oleh pihak ketiga jugạ diadakan larangan. GATT mengatur "exception" dalam pasal XX yang menyatakan :

"Subject to the requirement that suck a measures are not appled in a manner which would constitute a means of arbitrary or unjustiable discrimination between countries where the same condition prevail, or a disquized restriction on intemational trade, nothing in this agreement shall be construed to prevent the adoption on enforcement by any contracting party a measures :

a. necessary to protect human, animal or plant life or health, ...

b. necesšary to secure compliance with laws or regulations which are not inconsistent with the provisions of this agreement, including those relating to customs enforcement... a and the prevention of deceftive, practice... ${ }^{16}$

"Exception" yang dimuat dalam pasal XX (b) misalnya, dapat digunakan untuk menjustifikasi penerapan persyaratan terhadap barang impordalam hubungannya dengan eco-labelling.

14). Pasal $V: 5$ GATT

15). Lihat Pasal XI GATT.

16). Baca secara lengkap pasal XX GATT. 
4. Hubungán antara GATT dengan Perjanjian Lingkungan Internasional - dalam Perspektif Hukum Perjanjian Internasional

- - Sebagai bukti dari analisá dí atas, hubungan antara GATT dengan perjanjian lingkungan internasional merupakan sesuatu yang tidàk mudah; adakah suatu hirärchie norma-norma yang akan menentukan supremasi suatu peraturan, dimana peraturan yang satu lebih tinggi dari peraturan yang lain ?'GATT memberikan fleksibilitas yang sangat luas kepadanegara pesertauntuk mengaturpajak guna tujuan pelestarian lingkungan atau untuk tujuan-tujuan lain, sepanjang pajak semacam ini tidak mendiskriminasikan.

Dengan mengesampingkan apakah klasula "waiver" merupakan kebijaksanaan praktis untuk menghilangkan atau setidaktidaknya mengurangi konflik antara GATT dengan perjanjian, lingkungan internasional?. Keberadaan klasula "waiver" dalam GATT memberikan kesempatan kepada para pihak untuk mengesampingkan kewajiban-kewajiban yang diatur dalam GATT, sehingga tidak perlu ada konflik antara kewajibankewajiban negara di bawah perjanjian lain dengan kewajiban-kewajiban mereka. sebagai pihak dalam GATT ${ }^{17}$.

Hukum Perjanjian Internasional memberikan peraturan umum yang berisi nilai-nilai yang bermanfaatuntuk mengatasi jika terjadi perbedaan pendajpat. Peraturanperaturan umum itu antara lain :

- later treaties take priority over eărlier;

- more specific treaties take priority over the general-generalia specialibus non derogant;

- where a treaty'says that is subject to or is not considered incompatible with another treaty the other treaty will prevail; - as between parties to a treaty who later become parties to a later, inconsistent, treaty, the earlier will apply only where its provisions are not incompatible with. the later treaty.

Banyak permasalahan yang tidak . dapat di selesaikán dalam tulisan ini secara mendetail. Hal ini karena sulitnya menentukan prioritas yang mana antara GATT dengan bermacam-macam perjanjian lingkungan internasional. Pertama, karenakita berbicara masalah yang berbeda. Peraturan ini terutama difokuskan padakonflik dan prioritas antara perjarjianperjanjian yang mengatur súbyek yang' sama. Dalam hal ini kita mempunyai perjanjian yang berhubungan dengan lingkungan atau masalăh konservasi yang berisi pasal-pasal dalam bentuk instrumen perdagangan, namun disamping itu kita juga mempunyai hukum perdagangan intemasional, di mana untuk tujuan ini tercantum dalam aturan-aturan GATT yang telah direncanakan untuk mengatur bermacam-macam subyek, yang sering kita sebut liberalisasi perdagangan dunia. ${ }^{18}$

Masalah yang lebih rumit adalah bersumberdari sifatGATT itu sendiri, yaitu GATT tidak merupakan suatu perjanjian

17). Hal ini tidakdapat berarti bahwa klausula "waiver" yang ditawarkan oleh GATT dapat ditafsirkan sebagai cara yang sudah disiapkan GATT. Tetapi peizafsiran ýang benar ialah bahwa penggunaan klausula: "wainer" hanya dibenarka pada kasuskasus tertentu dan dalain waktu yang terbatas.

18). Namun demikian, dalam aturan GATT - itu sendiri engijinkan pemerintah suatu negara untuk menentukan Standard Lingkungan guna melindungi \& meningkatkan mutu lingkungan nasional. Baca perlakukan Nasional GATT (National Treatment). 
yang dapat diadopsi setiap saat. Oleh karena itu suatu negara yang akan mengadopsi harus dapat mengidentifikasi suatu moment yang tepat, misalnya pada tahun 1948 pada waktu pembentukan GATT atau pada waktu mengikuti putaran GATT.

Berlandaskan pada pembentukannya, meletakan GATT pada kedudukan yang kurang menguntungkan jika dihadapkan dengan perjanjian lingkungan yang lebih baru. Tetapi mungkin GATT akan menjadi tambahan dan pelengkap kerangka kerja untuk menganalisis perbedaan sifat perjanjian perdagangan dan perjanjian lingkúngan. Karena pada waktu pembentukannya GATT merupakan suatu perjanjian kontraktual, tanpa ada dukungan organisasi tetap, jadi GATT ini tidak dapat dikatakan sebagai badan legislatif Intemasional. Dan 'baru pada bulan Januari ini GATT, resmi. mempunyai organisasi yang disebut dengan WTO (World Trade Organization). Oleh karena itu sebelum terbentuknya WTO sebagai organisasi tetap GATT, GATT tidak dapat bersaing dengan agen-agen PBB sebagai pencipta legitimasi seperti yang digambarkan dalam hụkum internasional publik.

Kalau kita bandingkan GATT dengan perjanjian lingkungan yang sebagian besar menyangkut masalah kepentingan global, perjanjian lingkungan merupakan suatu contoh paradigma perjanjian yang dibuat berdasarkan kepentingart umum yang global. Hal ini menggambarkán kelompok negara-negara yang bertindak dalam kapasitas semi legislatif dan inherent dengan tujuan pengaturan masalah tertentu, yang diwujudkan dalam bentuk "constitutive treaty." ${ }^{19}$ Sebagaimana yang disebutkan oleh. Mc.Nair dalam hukum perjanjian intemasional, beliau membedakan antara perjanjian "erga omnes"20 dan perjanjian kontraktual yang menciptakan hak-hak . pribadi. Beliau berpendapat, bahwa perjanjian "erga omnes" dikarakterisasi oleh pemimpin-pemimpin negara untuk menentukan dan mengatasi masalah yang universal.

Perjanjian yang berhubungan dengan "global commons", seperti Vienna Convention, Montreal Protocol dan mungkin juga pada waktu yang akan datang."Climate Changè Convention", mereka nampaknya jatuh dalam kategori perjanjian erga omnes. Kemudian apakah perjanjian ini akan mempunyai tingkatan hukum yang lebih tinggi dan lebih superior daripada GATT ? Misalnya, apakah keberadaan pasal-pasal larangan impor tentang produk-produk yang mengandung "ozone depleting substances" dari negara-negara yang tidak menjadi peserta dalam perjanjian, hal ini dapat dijadikan alat untuk mendorong negaranegara menjadi peserta ? Sehingga perlu diciptakan suatu pasal khusus untuk memberlakukan perjanjian ini pada pihak ketiga. Tetapi masalah ini masih membutuhkan analisis yang lebih mendalam, sehingga apa yang disimpulkan . dalam makalah ini hanya merupakan kesimpulan sementara saja.

19). Mc. Nair, L. The Law of Treaties, (London Oxford University Press, 1961) hal: 259

20). Untuk mengetahui siapa saja yang dapat dikatagorikan sebagai "Erga Omnes" baca, H.M. Kindred, et al, International Law Chiefly as Interpreted and Applied in Canada, (Canada : Emond Montgomery Publications 1987) hal. 32. 
Dapat dikatakan, bahwa Montreal Protocol regime lebih diprioritaskan daripada GATT dalam hubungannya dengan perdagangan produk-produk yang mengandung "Ozone depleting substances". Sebab, "Ozone depleting substances" merùpakan subyek dalam Montreal Protocol. Tujuan Montreal Protocol adalah untuk mengatasi masalah "Ozone depleting substances" untuk kepentingan masyarakat intemasional secara keseluruhan. Pasalpasal perdagangan yang digunakan dalam Montreal Protocol dimaksudkan untuk mencapai apa yang menjadi tujuan perjanjian ini.

Selain itu seseorang dapat juga mengatakan bahwa menurut aturan umum yang disebutkan di atas, bahwa jenis perjanjian sepertiCITES merupakan contoh perjanjian khusus yang mempunyai prioritas terhadap perjanjian umum. Tanpa mengesampingkan pensyaratan (reservation) yang telah disebutkan mengenai suatu subyek yang sama, untuk menentukan suatu prioritas. Tentu saja apa yang diatur dalam CITES, yang secara eksplisit mengesampingkan aturan-aturan GATT dalam rangka untuk mengatasi masalah binatang langka menimbulkan suatu perdebatan. Sebab banyak negara-negara yang menjadi anggota CITES tetapi . sekaligus juga menjadi anggota GATT.

\section{Kesimpulan}

Konflik-konflik potensiall antara instrumen-instrumen perdagangan dalam perjanjian lingkungan internasional yang tidak däpat diselesaikan secara pasti oleh hukum perjanjian internasional menunjukkan adanya kebutuhan untuk mendiskusikan dan memformulasikan aturan-aturan baru. Jika aturan-aturan ini dimaksudkan untuk mengatasi masalahmasalah lingkungan, yang pada akhirnya méngarah pada keamanan global, maka perhatian harus ditumpahkan pada issueissue pembangunan dan peranan masyarakat internasional dalam transnasional corporation".

\section{DAFTAR PUSTAKA}

Brown Weciss, E, Environmental Change and International Law : The New Challenges and Dimensions. (Tokyo); United Nations Universsity Press, 1991)

Brunnee, J, International Environmental Law (Montreal: Mcgill University, 1990) -

nal Report of the Panel in the Matter of Canada's Landing Requirement for Pacific Coast Salmon and Herring, (16 Oktober 1989) Paragraph 7.02

GATT, "Study on Infernational Trade and Environment" (Pebruari 1992)

Gautama, S, Segi-segi Hukum Perdagangan Internasional (GATT dan GSP), (Bandung Citra Adityabakti, 1994)

Harris. D. J. Cases and Material on International Law, (london: Sweet \& Maxwell, 1991)

International Plenipotentiary Conference to Conclude an International Convention on Trade in Certain Species of Wildlife : Convention on International Trade in Endangered Species of wild Fauna and Flora, rerinted in (1986), 12 I.L.M. 1085

Kindred, H.M et al, International Law Chiefly as Interpreted and Applied in Canada (Canada: Emond Montgomery Publications 1987)

Lyster, S, Inteinational Wildlife Law, P 241

Mac Neill. J, et al, Beyond Interdependence: The Meshing of the Word's Economy and the Earth's Ecology (New York : 
Oxford University Press, 1991)

Mc Nair, L, The Law of Treaties, (London: Oxford University Press, 1961)

Montreal Protocol on Substence that Deplete the Ozone Layer (1987) 26 I.L.M

Porter. D.J, and Brown J. W, Global Environmentals Politics, Dilemas in word Politics, (Colorado: Wetsview Press. Inc, 1991)

- Report of the Panel, United States - Restriction on Import's of Tuna, (3 September 1991)

Sin Clair, The Vienna Convention on the law of Treaties, (2 nd.ed,1984)

Slocombo, D.S, "CITES, the Wildilife Trade and Sustainable Development" (1988), 16 (1) alternative 20 , dalam $D$. Vender
Zwaag, et.al, International Environmental Law (Nalifax : Dalihosie Law School, 1992) hal. : 290

Susskind, L.E., Environmental Diplomacy : Negotiating More Effective Global Agreement (New York: Oxford University Press, 1994)

United Nation Fremework Convention on Climate Change (1992) 31 I.L.M

UN Document, "International Environmental Law: Emerging Trendsand Implications for Transnational Corporations", (New York United Nations, 1993)

World Commissions on Environment and Development, Our Common Future (Oxford University Press, 1987) 